\title{
An analysis of the differences in corporate culture between China and Japan
}

\author{
Xin Feng \\ University of Reading, United Kingdom, RG6 6UA \\ 411266572@qq.com
}

Keywords: Corporate culture, culture comparison, Chinese corporate, Japanese corporate

\begin{abstract}
Corporate culture is defined as a company's social value, management skills, and group consciousness. Corporate culture is the method to deal with external and internal conflicts. In $21 \mathrm{st}$ century, corporate culture and business models attract more attention of researchers because if a company wants to go further, advanced and cohesive culture are really significant. This essay aims at analyzing the differences in corporate culture between China and Japan and provides suggestions to improve corporate culture effectively.
\end{abstract}

\section{Introduction}

Globalization is a national trend that promotes the economy of both developing and developed world. Higher level of cooperation starts to happen among organizations and other institutions. A company should have its own corporate culture and show respect to their partner's culture as well in order to survive. It is clear that there are huge differences between organization culture between China and Japan, which are originated from geological and background difference and there are considerable features can China learn from Japan to improve our original corporate culture system since it seems that Japanese corporate culture plays a leader role in front of the whole world because of its successful management skill. This essay will focus on the differences in corporate culture between China and Japan, analyzing why these differences exist, discussing the conflicts originated from various organization culture, giving suggestions on what China could learn from Japan.

\section{Comparison of Chinese and Japanese Culture Value}

\subsection{Section Headings}

There are similarities in culture between China and Japan, which is known as eastern culture system. Traditionally, this system pays more attention to benevolence, encouraging individuals to focus on discipline, the harmonies of human and society. However, Japanese culture is the combination of Asia and Europe. One the one hand, Japanese culture is at the edge of Asian culture because of its history. One the other hand, it accepted western culture largely in terms of education system, government policies. The interchange of the culture has positive effects for Japan to deal with international affairs and build great relationships with other countries.

\subsection{Features of Japanese Corporate Culture}

(1) Pursuits of economic benefits and serve the country. Most of time, the survival of Japan relies on governments' support. Government financial support is crucial because of shortage of land territory and resources. Government interests start to be one of the most significant part of all the corporations if managers would like to attract governments' funds.

(2) Staff training. Japanese government attach importance to the education of employee. The managers believe that technology and innovation of products are really crucial and these are all results of staffs' training, which is significant to improve employee's quality. An example of this is J-CAST, a well-know company in Japan, 'We mainly use e-learning training system to train stuff. It is different from both inner short time education and oral training. For example, when a student graduates from school, they sometimes can not blend into the company because of lacking of communication skills, thus we produce intact DVD for students to watch and grasp basic skills,' (Tai, 2009). This method happens frequently in Japanese firms, which is a great approach to train new staff and provide them with sufficient information about corporate culture before staff are fully employed, helping them to fit into the new environment better. 
(3) Collectivism and Individualism. Japanese culture is a combination of collectivism and individualism. The Japanese never satisfied with the spirit of learning so that they have long been influenced by the United States and other Western countries that individualism plays an important role. But they are also aware that extreme individualism will lead to social and organizational coordination difficulties. Only by integrating individualism into the group harmony can the individual's value in the group be fully exploited. So the staff tend to combine individualism with collectivism together to form the unique Japanese-style. In this kind of Japanese individualism, individual value is often reflected through the collective value and results. The attitude of self-concept and mutual help in Japan's work team plays an important role. It is this unique concept of culture that makes the enterprise in the form of such a form of decision-making, subtle goals and responsibilities.

(4) Employee oriented. Managers in Japan always pay attention to the staffs' feelings. They are willing to show respect, belief and concern to the employees. Japanese company prefer to give employees enough rest time. 'YAHOO', an IT company in Japan, gives their staff own choice to decide 2 days for rest in a week. Now the company is promoting to apply ' 3 days' rest in a week. Enough rest time could enable the staff to accompany their families and friends, thus staff will be grateful and be more energetic during their work hours. In addition, it is well known that Japan use life long employment system, which means Staff are able to serve for the company till retirement if they obey the rules and do not make huge problems for the firm. This system can bring all the workers a strong sense of belonging. They have a sense that the company they work in is just like their home and thus they will often emphasis on organizations' interests. A warm working environment is significant for every staff to show love and loyalty to the company, which will finally increase employees' motivation.

\subsection{Features of Chinese Corporate Culture}

(1) Pay attention to moral trait. Corporate culture in China has a strong sense of ethic codes. This is because China was influenced by Confucianism theory for a long time. Moral standards are criterion to judge manager's decision behavior. As a result, managers focus more attention on moral standards criteria instead of working efficiency.

(2) Individualism. Dispersal group dominate each corporation in China. These are sometimes consisted of relatives, friends who have close relationship, which will have negative effects on abuse of rights and motivation system.

To sum up, there are two main difference between corporate culture in China and Japan. Firstly, in Japan, managers pay attention to employee and try their best to improve welfare system across the nation while China tend to focus on short term interest gain and ignore the the feeling of employee frequently. In addition, the staff training system in Japan is more complete than China even though China is struggling to improve. It is demonstrated from the chart that Japan's minimum monthly salaries were highest among all the Asia countries, reaching to 1000 US dollars, it is mainly originated from their economy and welfare system. While China's salary still remained in lower level in Asia in 2016, which were around one thirds of Japan.

Table 1: The major difference in corporate culture

\begin{tabular}{|c|c|}
\hline Japan & China \\
\hline Staff training & Moral trait \\
\hline Employee oriented & Interest oriented \\
\hline
\end{tabular}




\section{Why these differences exist}

The geological environment between China and Japan is different. It is hard for China to communicate with outside word because its geological environment was closed in Ming dynasty which force Chinese civilization to have its own traditional color. At the same time, Chinese people have a sense of optimism. This is because the climate zone and latitude depends that China is a country suitable for crop growth, citizen's survival, thus they are unwilling to start reform. For Japanese citizens, they seldom feel satisfied and never stops learning. Japan is located in volcanic belt. They are influenced by earthquake, hurricane and tsunami frequently, encouraging Japanese to have perseverance to fight with nature disaster and have sense of national crisis. In addition, geological limitation enables this nation to expand territory, rely on other countries for help.

The increase number of multi-national companies enlarge the conflict management styles. This refers to manager's concept about rules, regulations, habits and motivation (Reis, 2016). Multinational companies contain employees from all over the world, making it hard to organize. The difference in corporate culture has a wide range of negative impacts on decision making and employee's demand. First of all, cultural diversity disturb decision making ability. Individuals from different background have various ways of thinking, which change their decision model. However, this can not be avoided in joint-investment company or multinational firm. People in different country have different working purpose and working standards. For instance, in China, working salary and performance bonus sometimes rank the first while in Japanese corporation, the most significant issue for workers is making contributions to the company they worked in.

\section{What China can learn from Japan}

With the acceleration of global economy, organizations face dramatic challenges. It is illustrated from the table below that China's participation in international market is increasing from 1994 to 2004. Manage multinational company might be one of the crucial part for operation of company. It is accepted by most of people that Japanese corporate culture is more suitable to global market and it is wise for China to learn something from Japan to improve corporation management.

4.1 Cultivate talented staff. Employee with great talents are significant part for company's working efficiency. In China, brain drain is a common phenomenon, which means even though elited staff is recruited, sometimes managers in company is unable to retain them. While in Japan, it is a rather reversal. China could emphasize more on staff training, reward mechanism and promotion system to improve the loyalty of the staff. It is shown from the chart below that the salary gap in cities in China is huge and the there is significant difference between maximum and average wage. Maximum salaries in cities such as Shanghai, Beijing, Guangzhou rank relatively high. It is illustrated that the highest salaries in these cities are three times higher than average. This resulted in most of the talented people concentrate on working in prosperous these cities for better job opportunities and promotion chance. Overall, narrowing the wage gap between cities is an essential method to ensure balanced development and talented staff will not consider about changing their job to developed cities. However, it is wise to increase the salary gap between the staff to stimulate their working motivation.

4.2 Improve staffs' agreement on corporate culture. Unique corporate culture in each firm is fundamental to sustainable development. In order to survive in the harsh competition, using corporate culture to improve the image of company is a wise method. To some company, corporate culture seems to be a useless paper because managers do not put them into practice. However, managers act as a significant role in the whole process of cultivating employees' motivation. There is no doubt that managers ought to pay more attention to their own behavior to create an example for employees. Regulations and standards could be set to regulate the staffs' behavior.

4.3 The combination of corporate culture with social development. The initial purpose a company is to make contributions to society. In China, some managers have not fully made national responsibility as company's mission and pay large attention to interests. If this continues, it is hard to 
ensure sustainable development. As a result, when a company was founded, managers should consider both short term interest gains and social responsibility. It is significant to consider carefully about what to achieve. In this point, 'Haier', a household applications company make a great success. It has the purpose of establish the global brand and make this Chinese brand popular across the world when it is founded. They try to achieve this by making donations to poor citizens, helping disabled individuals and making donations to some fields such as sports and education. They remember to return back to society when they gain profits. This helps the corporation to gain fame and support from customers. Overall, the combination of corporate culture with social responsibility allows firm to improve customer's satisfaction and improve employee's loyalty.

\section{Conclusion}

The number of multinational companies has risen dramatically recently both in China and Japan with the trend of globalization. Improving corporate culture is significant for corporations to survive in harsh competition. It is clear that there are huge differences in corporate culture between these two countries, which increase the conflicts for management. It is accepted that Japanese corporate culture is more suitable to global market and it is wise for China to learn from Japan by attracting talented staff, improving staff training system and combining corporate culture with social development to ensure sustainable development.

\section{References}

[1] Aspalter, C. (2001). Welfare State Systems in Japan and China: Past Changes and Challenges. Researchgate, 32-56.

[2] Ergune, L. (2008). Creating an Organizational Culture that Promotes Healthy Conflict. Organization Development Journal, 15(4), pp51-65.

[3] Ergune, L. (2008). Creating an Organizational Culture that Promotes Healthy Conflict. Organization Development Journal, 15(4), pp51-65.

[4] Purser, R. (1994). Guest edutiral 'Shallow' versus 'deep' organizational development and environmental sutainability. Journal of Organizational Change Management 7(4): pp 4-14

[5] Paulo, S. (2017). Collaboration and crisis in merge projects: a study in cross corporate culture conflict and its education. Independent Journal of Management \& Production, 8(2), pp 395-415.

[6] Schein, L. (2008). How Leaders Shape Conflict Cultures and Their Organizational-Level Consequences. Journal of Applied Psychology, 97(6), pp1131-1147. 